\title{
Can we improve ocular blood flow and protect the eye?
}

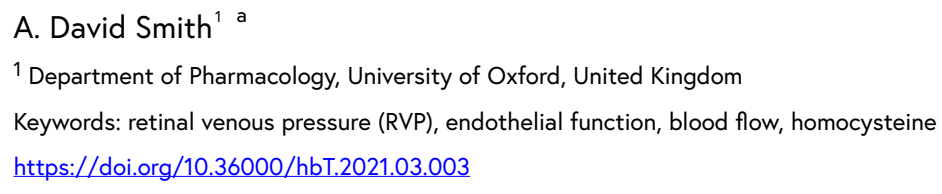

healthbook TIMES Das Schweizer Ärztejournal Journal Des Médecins Suisse

Vol. 3, Issue 3, 2021

Maintenance of a good blood flow through the eye is crucial and impairment or dysregulation of blood flow is a likely cause of several diseases of the eye. In particular, raised retinal venous pressure (RVP) has many adverse effects. ${ }^{1}$ The blood vessels in the retina are unusual in that they are not innervated by autonomic nerves and the control of blood flow is largely mediated by local release of vasoactive substances, mainly from the vascular endothelium. Hence, impaired blood flow is often the consequence of the impaired function of the vascular endothelium (vascular endotheliopathy), which can be caused by hypertension, diabetes, oxidative stress and raised plasma homocysteine (Figure 1), or by primary vascular dysregulation (the Flammer syndrome). ${ }^{2,3}$

Although there are pharmacological approaches to improving vascular endothelial function, these may be accompanied by unwanted side effects. An alternative approach is to treat the patient with nutrients that have known beneficial actions on the endothelium. Perhaps the most important factor that reflects the health of the vascular endothelium is the production and action of nitric oxide. So we need to identify treatments that improve nitric oxide bioavailability and stability. As in other vascular beds, nitric oxide plays a key role in maintaining normal vascular function in the eye, ${ }^{6}$ where it probably mediates both arterial and venous dilation, ${ }^{7}$ increased blood flow and reduced intraocular pressure. ${ }^{8}$ Some substances that can improve nitric oxide bioavailability are shown in Figure 1. Several of these substances have additional beneficial effects, such as lowering the concentration of homocysteine - an amino acid that is toxic to the endothelium. These substances include the bioactive natural form of folate - L-methyl folate, which both increases the production of nitric oxide and lowers homocysteine. ${ }^{9,10}$ Raised homocysteine is an established risk factor for many vascular and brain diseases ${ }^{11}$ and for retinal vascular occlusive disease, ${ }^{12}$ diabetic retinopathy ${ }^{5,13}$ and age-related macular degeneration. ${ }^{14}$

\footnotetext{
a Corresponding author:

Prof. emer. Dr A. David Smith

Mansfield Rd

Oxford OX1 3QT

United Kingdom

Email: david.smith@pharm.ox.ac.uk
} 


\section{Impaired by}

Hypertension

Diabetes

Oxidative stress

Homocysteine
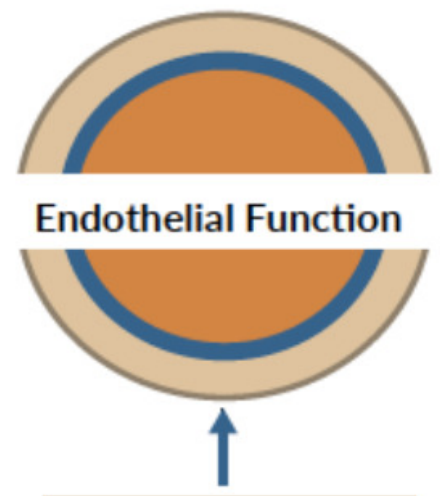

Nitric oxide

bioavailability

\section{Improved by}

Methylfolate

Methyl-B12

Riboflavin

Zinc

Antioxidants

- vitamins C \& E

- $\mathrm{N}$-acetylcysteine

- lutein

- zeaxanthin

Figure 1. Some factors influencing endothelial function.

The substances listed on the right are all present ${ }^{4}$ in Ocufolin ${ }^{\circledR}$. Adapted from Shi et al. ${ }^{5}$

Homocysteine concentrations are influenced by common genetic polymorphisms but are mainly determined by the status of two $B$ vitamins, folate and vitamin B12. In a significant proportion of the population, the B vitamin status is suboptimal, leading to modestly raised homocysteine, which can be corrected by taking B vitamins. Folate is probably the most relevant $B$ vitamin: methylfolate supplies the methyl group that converts homocysteine to methionine, so regenerating an essential amino acid and lowering homocysteine levels. Folic acid, a synthetic substance that is not equivalent to methylfolate, is widely used as a supplement, but there are concerns about its adverse effects. ${ }^{15,16}$

There is no single factor that can alleviate impaired blood flow in the eye: a combination of different substances is needed to enhance nitric oxide bioavailability and lower homocysteine. A commercial medical food called Ocufolin ${ }^{\circledR}$ contains methyl folate and several other key ingredients which act as antioxidants, some of which also lower homocysteine, such as $\mathrm{N}$ acetylcysteine ${ }^{17}$ and zinc. ${ }^{18}$ Furthermore, under certain circumstances, the $\mathrm{B}$ vitamins B2, B6 and B12 also lower homocysteine. ${ }^{11}$

In preliminary studies, Ocufolin ${ }^{\circledR}$ has been shown to improve symptoms in diabetic and hypertensive retinopathy even in long-standing cases, ${ }^{4}$ with the resolution of retinal hemorrhages and microaneurysms and the reduction of exudates and macular edema. Furthermore, Ocufolin ${ }^{\circledR}$ markedly lowered plasma homocysteine in diabetic patients by an average of $32 \%{ }^{19}$ and it lowered retinal venous pressure in a pilot study (unpublished). Because Ocufolin ${ }^{\circledR}$ is 
scientifically formulated and contains only natural nutrients, it is safe and without adverse side effects. Furthermore, as well as being beneficial to the eye, the ingredients have more general benefits for the cardiovascular and nervous systems. ${ }^{11}$

\section{Conflict of Interest}

ADS is on the scientific advisory board of Aprofol.

Submitted: August 31, 2021 CEST, Accepted: October 03, 2021 CEST 


\section{REFERENCES}

1. Flammer J, Konieczka K. Retinal venous pressure: the role of endothelin. EPMAJ. 2015;6:21. doi:10.1186/s13167-015-0043-1

2. Flammer J, Konieczka K. The discovery of the Flammer syndrome: a historical and personal perspective. EPMAJ. 2017;8(2):75-97. doi:10.1007/s13167-017-0090-x

3. Barthelmes J, Nägele MP, Ludovici V, Ruschitzka F, Sudano I, Flammer J. Endothelial dysfunction in cardiovascular disease and Flammer syndrome-similarities and differences. EPMAJ. 2017;8(2):99-109. doi:10.1007/s13167-017-0099-1

4. Wang J, Brown C, Shi C, et al. Improving diabetic and hypertensive retinopathy with a medical food containing L-methylfolate: a preliminary report. Eye Vis (Lond). 2019;6:21. doi:10.1186/ $\underline{\text { s40662-019-0147-0 }}$

5. Shi C, Wang P, Airen S, et al. Nutritional and medical food therapies for diabetic retinopathy. Eye Vis (Lond). 2020;7:33. doi:10.1186/s40662-020-00199-y

6. Dorner GT, Garhofer G, Kiss B, et al. Nitric oxide regulates retinal vascular tone in humans. Am J Physiol Heart Circ Physiol. 2003;285(2):H631-636. doi:10.1152/ajpheart.00111.2003

7. Gugleta K, Zawinka C, Rickenbacher I, et al. Analysis of retinal vasodilation after flicker light stimulation in relation to vasospastic propensity. Invest Ophthalmol Vis Sci. 2006;47(9):4034-4041. doi:10.1167/iovs.06-0351

8. Wareham LK, Buys ES, Sappington RM. The nitric oxide-guanylate cyclase pathway and glaucoma. Nitric Oxide. 2018;77:75-87. doi:10.1016/j.niox.2018.04.010

9. Antoniades C, Shirodaria C, Warrick N, et al. 5-Methyltetrahydrofolate rapidly improves endothelial function and decreases superoxide production in human vessels. Effects on vascular tetrahydrobiopterin availability and endothelial nitric oxide synthase coupling. Circulation. 2006;114:1193-1201. doi:10.1161/CIRCULATIONAHA.106.612325

10. Yuyun MF, Ng LL, Ng GA. Endothelial dysfunction, endothelial nitric oxide bioavailability, tetrahydrobiopterin, and 5-methyltetrahydrofolate in cardiovascular disease. Where are we with therapy?. Microvasc Res. 2018;119:7-12. doi:10.1016/j.mvr.2018.03.012

11. Smith AD, Refsum H. Homocysteine - from disease biomarker to disease prevention.J Intern Med. 2021;290(4):826-854. doi:10.1111/joim.13279

12. Abu El-Asrar AM, Abdel Gader AG, Al-Amro SA, Al-Attas OS. Hyperhomocysteinemia and retinal vascular occlusive disease. Eur J Ophthalmol. 2002;12(6):495-500. doi:10.1177/

$\underline{112067210201200608}$

13. Lei X, Zeng G, Zhang Y, et al. Association between homocysteine level and the risk of diabetic retinopathy: a systematic review and meta-analysis. Diabetol Metab Syndr. 2018;10:61.

doi:10.1186/s13098-018-0362-1

14. Huang P, Wang F, Sah BK, et al. Homocysteine and the risk of age-related macular degeneration: a systematic review and meta-analysis. Sci Rep. 2015;5:10585. doi:10.1038/ $\underline{\operatorname{srep} 10585}$

15. Smith AD, Kim YI, Refsum H. Is folic acid good for everyone?. Am JClin Nutr. 2008;87(3):517-533. doi:10.1093/ajcn/87.3.517

16. Selhub J, Rosenberg IH. Excessive folic acid intake and relation to adverse health outcome. Biochimie. 2016;126:71-78. doi:10.1016/j.biochi.2016.04.010

17. Hildebrandt W, Sauer R, Bonaterra G, Dugi KA, Edler L, Kinscherf R. Oral N-acetylcysteine reduces plasma homocysteine concentrations regardless of lipid or smoking status. Am J Clin Nutr. 2015;102(5):1014-1024. doi:10.3945/ajcn.114.101964 
18. Pakfetrat M, Shahroodi JR, Zolgadr AA, Larie HA, Nikoo MH, Malekmakan L. Effects of zinc supplement on plasma homocysteine level in end-stage renal disease patients: a double-blind randomized clinical trial. Biol Trace Elem Res. 2013;153(1-3):11-15. doi:10.1007/ $\underline{\text { s12011-013-9639-2 }}$

19. Schmidl D, Howorka K, Szegedi S, et al. A pilot study to assess the effect of a three-month vitamin supplementation containing L-methylfolate on systemic homocysteine plasma concentrations and retinal blood flow in patients with diabetes. Mol Vis. 2020;26:326-333. 


\section{SUPPLEMENTARY MATERIALS}

Can we improve ocular blood flow and protect the eye?

Download: https://schw-aerztej.healthbooktimes.org/article/30183-can-we-improve-ocular-blood-flowand-protect-the-eye/attachment/76842.pdf 